Revista Eletrônica do Mestrado em Educação Ambiental

Programa de Pós-Graduação em Educação Ambienta1

\title{
Pedagogia das Ruas como práxis de resistência
}

\author{
Alvaro Luis Avila da Cunha ${ }^{1}$ \\ Universidade Federal do Pampa \\ ORCID https://orcid.org/0000-0002-7577-5615
}

Resumo: Este ensaio pretende responder a chamada do XI Encontro e Diálogos em Educação Ambiental (EDEA), apresentando em um primeiro momento as bases epistemológicas que sustentam minhas práticas pedagógicas no âmbito universitário e escolar, reafirmando o socialismo ambiental como uma das possibilidades de enfrentamento ao capitalismo globalitário neoliberal fortalecido na última década pelo ressurgimento de posturas políticas totalitárias. Logo a seguir descrevo como no âmbito universitário venho construindo umapráxis pedagógica com graduandos e duas comunidades escolares de Uruguaiana focando nas ações desenvolvidos pelo Componente Curricular Complementar de Graduação Movimento e Ambiente e pelo Grupo de Estudos Movimento e Ambiente neste ano de 2019.

Palavras-chave: socialismoambiente praxis pedagógica

\section{La pedagogía de las calles como praxis de resistencia}

Resumen: Este ensayo tiene como objetivo responder al llamado de la XI Reunión y Diálogos en Educación Ambiental, presentando al principio las referencias teóricas que respaldan mis prácticas pedagógicas en el entorno universitario y escolar, reafirmando el socialism ambiental como una de las posibilidades de confrontar el capitalismo global neoliberal fortalecido en la última década por el resurgimiento de posturas políticas totalitarias. A continuación describe cómo en la universidad he estado construyendo una praxis pedagógica con estudiantes universitarios y dos comunidades escolares en Uruguay, centrándome en las acciones desarrolladas por CCCG Movimento e Ambiente y por el Grupo de Estudio Movamento e Ambiente este año 2019.

Palabras clave: socialismo, ambiente, praxis pedagógica.

\section{Streets Pedagogy as práxis of resistance}

Abstract: This essay aims to answer the call of the XI Meeting and Dialogues in Environmental Education, presenting at first the theoretical references that support my pedagogical practices in the university and school environment, reaffirming environmental socialism as one of the possibilities of confronting neoliberal globalitarian capitalism strengthened over the past decade by the

1 Licenciatura Pena em Educação Física. Mestre em Educação. Doutor em Educação Ambiental. e-mail: alvaro.balas@gmail.com

Rev. Eletrônica Mestr. Educ. Ambient. Rio Grande. v. 37, n. 3. Seção especial: XI EDEA - Encontro e Diálogos com a Educação Ambiental. p. 365-378. mai./ago. 2020.

E-ISSN 1517-1256 
resurgence of totalitarian political stances. Below I describe how in the university I have been building a pedagogical praxis with undergraduates and two school communities in Uruguay focusing on the actions developed by CCCG Movimento e Ambiente and by the Movamento e Ambiente Study Group this year 2019.

Keywords: socialism environment pedagogical praxis

\section{Introdução}

Este ensaio propõe a cidade como currículo e uma práxis docente orientada por uma Pedagogia das Ruas. Paulo Freire em uma de suas últimas entrevistas dizia que a educação deveria ser invadida por pedagogias, pois são variados os desafios nesta sociedade/mundo, onde opulência e miséria se manifestam tão explicitamente e as desigualdades sociais se justificam por um revigorado darwinismo social neoliberal.

Neste sentido o XI EDEA é bastante propositivo em sua chamada, para existir em tempos de retrocesso, precisamos reafirmar de forma explícita nossas concepções de sociedade/mundo. E é isto que faço na primeira parte deste trabalho para a seguir refletir a práxis pedagógica dos últimos meses do Grupo de Estudos Movimento e Ambiente e o Componente Curricular Movimento e Ambiente, que há alguns anos vem contribuindo na ambientalização curricular em cursos de formação de professores e graduações na área da saúde. Gostaria de apresentar como tem sido nossos últimos diálogos com escolas públicas de Uruguaiana localizadas às margens do rio Uruguai e arroios afluentes, avaliando como vem se estabelecendo esta comunicação; também apresentaremos as produções textuais baseadas nos registros de campo dos acadêmicos dos cursos de Licenciatura em Educação Física e Ciências da Natureza, além da Enfermagem, Farmácia e Veterinária.

Nestes relatos verificamos como @s acadêmico@as vem apreendendo a perspectiva ambiental na sua formação, ao mesmo tempo que revelam saberes ambientais apreendidos durante as trilhas urbanas.

\section{Concepção}

O XI EDEA interpela e nos convida a analisar o contexto mundial que estamos imersos nesta última década do século XXI. Sendo assim com todas as limitações de uma classificação, posso afirmar o pensamento crítico e pós-crítico e o marxismo frankfurtiano do século XX como fundamentos de minha práxis, no sentido que Marx e Engels emprestam à palavra, na segunda Tese ad Feuerbach: 
A questão de atribuir ao pensamento humano uma verdade objetiva não é uma questão teórica, mas prática. É na práxis que o homem deve demonstrar a verdade, isto é, a realidade e a força, o caráter terreno de seu pensamento (MARX e ENGELS, 1987, p. 120).

E incorporada por Freire, na Pedagogia do Oprimido:

É preciso que fique claro que, por isto mesmo que estamos defendendo a práxis, a teoria do fazer, não estamos propondo nenhuma dicotomia de que resultasse que este fazer se dividisse em uma etapa de reflexão e outra, distante, de ação. Ação e reflexão se dão simultaneamente (FREIRE, 2004, p. 125).

É com este referencial que leio o contexto proposto pelo Encontro; contexto este em que a perspectiva fascista de mundo retorna 80 anos depois de gestada pelo modelo bélico industrial capitalista na Itália, Alemanha e Espanha, aparentemente derrotada na segunda grande guerra; mas como nos dizia o rock gaúcho "o fascismo é fascinante e deixa gente ignorante fascinada". O mais absurdo são estas formas primitivas de política, que tem a padronização e a violência como linguagem, conseguirem suas vitórias políticas utilizando-se das redes sociais como plataforma estratégica perfeita, para desespero de pensadores como Pierre Levy que acreditava nas redes sociais e WEB como elemento democrático por excelência. As redes permitem uma produção e centralização de informação incríveis, logo o controle deste mecanismo permite construir realidades, cenários, conduzindo seus personagens e aflorando totalitarismos. Logo, conceitos como direita e esquerda que a pós modernidade sepultara, retornam de forma pragmática, explícita e violenta.

\section{O socialismo ecológico e sua atualidade no final de segunda década do século XXI}

Resenha-fábula sobre Ecomunitarismo

Era uma vez um reino chamado Ecomunitário...

Havia três leis para a conduta de seus habitantes.

Uma que versava sobre a dimensão libertária de todo e qualquer ser humano; a segunda envolvia o entendimento da necessidade de se estabelecer acordos, uma responsabilidade coletiva; e, por fim, a última, lembrava de cuidar da saúde do planeta que sustentava o reino.

Simples assim construiu-se a fórmula ética, verdade possível, possibilidade sempre provisória do universal, mínimo consenso para que homens e mulheres pudessem se autonomear humanos e humanidade. 
Dizem os antigos da existência, antes do reino ser reino, de um filósofo chamado Sirio, aliás, Roberto, que já teria previsto tais leis e escrito através de um mais antigo dialeto chamado lógica formal, que dizia:

1-Devo garantir minha liberdade de decisão porque eu garanto minha liberdade de decisão é condição de eu faço a pergunta "Que devo fazer?"

2-Devo buscar consensualmente uma resposta para cada instância da pergunta "Que devo fazer?"Por que eu busco consensualmente uma resposta para cada instância da pergunta "Que devo fazer?” É condição da pergunta "Que devo fazer?"

3-Devo preservar uma natureza saudável do ponto de vista produtivo porque eu preservo uma natureza saudável do ponto de vista produtivo é condição de eu faço a pergunta "Que devo fazer?"

Além disso, o filósofo se valeria de mais dois paradigmas científicos: o materialismo histórico-dialético e a teoria conhecida como dos sistemas.

Indivíduo sociedade natureza inconcebíveis separadamente.

Toda vez que respiro, estou vivenciando essa tríade: Sou livre natureza dentro de um consenso social. Talvez resida aí a possibilidade revolucionária da condição humana: somos condição e indeterminismo.

Por que escolher o Socialismo Ecológico como perspectiva em Educação Ambiental no capitalismo neoliberal globalitário?

$\mathrm{Na}$ verdade, trata-se de honrar uma tradição que parece vigorosa o suficiente para confrontar a apatia calorosa ou o "delicioso despotismo" 2 em que seencontram imersas as sociedades contemporâneas. Honrar uma tradição não significa simplesmente justificar o marxismo e o pensamento ecológico como referenciais de análise e ação.

Talvez devêssemos falar primeiro em uma tradição romântica ${ }^{3}$, importante e pioneira força a rebelar-se contra o embrutecimento do modelo de vida proposto pela modernidade, voltando-se contra o império da razão-instrumento, da razão-funcionalidade, da razão- produtividade.

Mesmo se fizéssemos a interpretação mais mecanicista e fria do materialismo histórico-dialético, mesmo que quiséssemos reduzir o pensamento marxista à pura ciência e deduzir desta o futuro da humanidade, ainda assim não poderíamos deixar de contar com uma espécie de crença ou fé.

No momento em que acreditamos na possibilidade humana de alterar suas rotas, inverter seus caminhos, frear seus frenéticos ritmos de produção, consumo e de gozos efêmeros e regulados; neste momento estamos encharcados de romantismo. Equivocado dizer que o romantismo por si só seja uma força revolucionária, mas revoluções aconteceram e acontecem somente mediante a presença desse ingrediente básico.

\footnotetext{
${ }^{2}$ Expressão cunhada por Ignácio Ramonet, em seu livro denominado Propagandas Silenciosas.

${ }^{3}$ Quem me chamou a atenção para as influências do movimento romântico nas correntes libertárias de cunho socialista e as proximidades com as bases do movimento ecológico foi Michael Lowy, em seu artigo De Marx ao Ecossocialismo e a resenha do livro Revolta e Melancolia - o romantismo na contramão da modernidade (Lowy e Sayre) por Isabel Maria Loureiro; ambos os textos fazem parte do livro Marxismo, Modernidade e Utopia (Lowy e Bensaid).
}

Rev. Eletrônica Mestr. Educ. Ambient. Rio Grande. v. 37, n. 3. Seção especial: XI EDEA - Encontro e Diálogos com a Educação Ambiental. p. 365-378. mai./ago. 2020.

E-ISSN 1517-1256 
Os românticos e seus romances denunciavam as condições cada vez piores de vida das sociedades em franco processo de urbanização e metropolização, da mesma forma como os ambientalistas arremessaram-se e se arremessam contra os modelos predatórios e insustentáveis da economia pós-industrial. Assim, estão mantendo a chama daqueles que pensavam poder resgatar o paraíso perdido que a humanidade, no seu sombrio caminho civilizador, deixou de construir.

Talvez seja uma perspectiva romântica ${ }^{4}$ que me identifica com o pensamento ecomunitário de Sírio, pois na sociedade contemporânea, em que o objetivo de cada pessoa é ser o número 1, não importando "em que", ou do que sejamos capazes de fazer para "chegar lá", afirmar uma possibilidade ética universal que retira do imperativo pessoal individualista "querer" para a perspectiva social "dever" é jogar-se contra moinhos de vento, hoje neoliberais e globalitários.

Creio que é um "universal humano" presente em todas as culturas o fato das pessoas se perguntarem: "Que devo fazer?" (em uma ou outra circunstância) e essa pregunta contém o peso de uma auto-obrigação que, se não cumprida, independente de qual seja a opinião de outro sou a sanção ou prêmio social, deixa na pessoa o desagradável sabor da insatisfação para consigo mesma. Esta auto-obrigação é própria da ética e da moral (VELASCO, 2000, p. 132). [traduçãolivre]

No entanto, torna-se também referencial precioso na práxis daqueles/as que lutam pela quebra do que ainda poderíamos chamar de hegemonia cultural ou de Ideologia da Sociedade Industrial (Unidimensional man), descrita por Herbert Marcuse há cincoenta anos. "Nós nos submetemos à produção pacífica dos meios de destruição, à perfeição do desperdício, a ser educados para uma defesa que deforma os defensores e aquilo que estes defendem" (1967, p. 13).

Marx parece deixar claro a relação homem natureza, ao afirmar:

O homem vive da natureza significa: a natureza é o seu corpo, com o qual ele tem que ficar num processo contínuo para não morrer. Que a vida física e mental do homem está interconectada com a natureza não tem outro sentido senão que a natureza está interconectada consigo mesma, pois o homem é uma parte da natureza (2004, p.84)

E, logo depois, cita a civilização mesopotâmica e grega e também de outras regiões, que devastaram recursos naturais e tiveram seu declínio também associado a tais práticas predatórias.

${ }^{4} \mathrm{O}$ ecossocialista Daniel Bensaid sinaliza ser o romantismo matriz comum tanto a marxistas como a ecologistas.

Rev. Eletrônica Mestr. Educ. Ambient. Rio Grande. v. 37, n. 3. Seção especial: XI EDEA - Encontro e Diálogos com a Educação Ambiental. p. 365-378. mai./ago. 2020. 
Marx,continua, nos Manuscritos, reforçando os elos entre homem e natureza:

A universalidade do homem aparece praticamente na universalidade que faz de toda a natureza o seu corpo inorgânico: 1) como imediato meio de vida; e igualmente 2) como objeto material e instrumento de sua atividade vital. A natureza é o corpo inorgânico do homem, ou seja, a natureza na medida em que não é o próprio corpo humano. O homem vive da natureza, ou também, a natureza é o seu corpo, com o qual tem de manter-se em permanente intercâmbio para não morrer. Afirmar que a vida física e espiritual do homem e a natureza são interdependentes significa apenas que a natureza se inter-relaciona consigo mesma, já que o homem é uma parte da natureza (MARX, 2002, p. 116).

Autores, como John Bellamy Foster, acreditam que a teoria marxista, por si só, já apresentaria elementos significativos que apontam concretamente para uma visão ecológica, a ponto de intitular seu livro A Ecologia de Marx: Materialismo e Natureza.

Embora haja uma longa história de denúncias contra Marx por falta de preocupação ecológica, hoje, após décadas de debate, está claríssimo que esta visão absolutamente não condiz com as evidências. Pelo contrário, como observou o geógrafo italiano MassimoQuaini, 'Marx (...) denunciou a espoliação da natureza antes do nascimento de uma moderna consciência ecológica burguesa'. Desde o princípio, a noção de Marx de alienação do trabalho humano esteve conectada a uma compreensão da alienação dos seres humanos em relação à natureza (2005, p. 23).

Foster, entre tantas outras descobertas, explora a riqueza do conceito de "metabolismo", utilizado por Marx no livro O Capital, como sendo a relação existente entre homens e natureza e que, com o avanço dos modos de produção capitalista e sua divisão de trabalho, cristaliza-se uma falha metabólica irreparável no processo referido. Uma contradição que se estabelece entre cidade e campo, homem e terra. Marx usará como exemplo a agricultura capitalista inglesa que, ao acabar com a fertilidade de seu solo pelo uso intensivo, teve que importar guano do Peru, o que provaria para o filósofo alemão a insustentabilidade do sistema capitalista. Foster ainda lembra que o conceito de metabolismo continua em vigor entre os ecólogos e para a teoria de sistemas (ODUM, 1970).

De outro lado, para além ou aquém de meu romantismo, meu vínculo se estabelece pelo referencial dialético marxista e freiriano em que o ecomunitarismo se alicerça, principalmente nas categorias alienação do trabalho e diálogo, respectivamente; categorias e referenciais tão caros a nós, educadores/as licenciados/as no início dos anos oitenta, que tínhamos neles nossas principais ferramentas de enfrentamento ao regime militar, 
implantado em 1964, no Brasil, e de perspectiva da conquista de uma sociedade justa e "verdadeiramente" democrática. Ainda acredito serem essas as ferramentas epistemológicas mais preciosas em minha prática dentro da estrutura escolar, educacional e social, haja vista o retorno do regime militar no Brasil 01/2019.

Superar a alienação através do diálogo e de práticas desestabilizantes da ordem capitalista constituiu-se, durante vinte anos, o verdadeiro mote de minha prática docente.

É na crença em questão, qual seja, a da necessidade de outra possibilidade civilizatória, que não a oferecida pelo capital e seus preciosos valores, receitas fastfood, centros de consumo e cegueira tecnológica, que integro a perspectiva ecomunitarista. Pois reconheço ser este seu leitmotiv, pelo qual também eu sempre busquei me orientar.

Foi na construção de outras possibilidades para o ser humano neste planeta que nasceu a tentativa de estabelecer um referencial ético universal capaz de reorientar os rumos sociais a partir da pergunta instauradora da ética "que devo fazer?" e as três normas éticas ${ }^{5}$ que a sucedem.

A caminhada ecomunitarista é sustentada ou tem como suporte e ferramenta básica a ética argumentativa, que, por sua vez, tem seu critério de veracidade na estrutura lógicolinguística; nessa capacidade de formular assertivas que, graças à cuidadosa elaboração, aproximam-se de certezas ou de verdades cientificamente comprovadas. Mas seria possível deduzir leis de comportamento a partir de uma matemática da linguagem, em que se assegurasse uma verdade universal? Nesse aspecto, entendi que não podemos perceber o ecomunitarismo somente preso a este paradigma, uma vez que se utiliza claramente de outros dois: o dialético e o da teoria dos sistemas.

Creio que a relação a se estabelecer entre a lógica clássica e a lógica dialética é parecida com aquela que se estabelece entre a física newtoniana e a física relativista. A primeira é adequada a fenômenos macroscópicos cujas velocidades são escassas em relação à velocidade da luz, mas deixa de sê-lo na presença do mundo atômico e subatômico. A lógica formal pode considerar-se adequada quando: a) tratamos com "enunciados", b) desprezamos as conexões sistêmicas globais adotando uma visão setorial, c) e descartamos o fator "tempo". Quando, ao contrário, utilizamos a linguagem mais que enunciados, temos pretensões sistêmicas e/ou queremos incorporar "à analise o fator tempo, sob forma de "movimento" ou ainda de "História", então a lógica formal mostra-se

\footnotetext{
${ }^{5}$ As três normas éticas: $1^{\text {a }}$ Devo garantir minha liberdade de decisão porque Eu garanto minha liberdade de decisão é condição de Eu faço a pergunta: Que devo fazer? (numa realização feliz). $2^{\text {a }}$ Devo buscar consensualmente uma resposta para cada instância da pergunta Que devo fazer? Por que Eu busco consensualmente a resposta para cada instância da pergunta Que devo fazer? é condição de a pergunta Que devo fazer? ser feliz; $3^{\mathrm{a}}$ Devo preservar uma natureza saudável do ponto de vista produtivo porque Eu preservo uma natureza saudável do ponto de vista produtivo é condição de Eu faço a pergunta Que devo fazer?
}

Rev. Eletrônica Mestr. Educ. Ambient. Rio Grande. v. 37, n. 3. Seção especial: XI EDEA - Encontro e Diálogos com a Educação Ambiental. p. 365-378. mai./ago. 2020.

E-ISSN 1517-1256 
inadequada. Nestes casos, em especial nos últimos, cabe usar a lógica dialética (VELASCO, 2008, p. 42-3).

Admito a necessidade de uma resposta universal aos problemas produzidos pela sociedade globalitária capitalista, que espalhou suas marcas por quase a totalidade do território terrestre e estendeu sua lógica mercantilista e predatória a quase todas as tribos em quase todos os portos, banhados e restingas. Para responder à irresistível força que autores como Negri, Hardt, Petras, Galeano, Harvey denominam de Império, outras forças poderiam ser integradas, somadas e fundamentadas. Para tanto, faz-se necessário o diálogo. Não qualquer relação dialógica, mas o diálogo que assume compromisso, comprometido, diálogo que encaminha a luta pela vida, em uma disputa Pela Humanidade e Contra o Neoliberalismo,como foi chamado pelos insurgentes rebeldes mexicanos de Chiapas (1997), e que encaminhou para a posterior realização dos quatro Fóruns Sociais Mundiais e tantos outros foros espalhados pelo mundo na última década do século XX e primeira do século XXI. Nessas tentativas de entendimento e encaminhamento dos embates contra o capital em nível mundial, me faz parecer que toda aquela pluralidade ali reunida tenta responder uma pergunta básica: "Que devemos fazer?"

A resposta à referida pergunta pressuporia: liberdade de opção (ou tanto quanto seja possível); uma resposta amparada no coletivo, construída através de exaustivo e/ou prazeroso diálogo na busca do convencimento mútuo (com - vencer, vencer junto); e, por último, que nossas ações não atentassem contra a vida não humana, da qual não podemos nos dissociar, já que, em uma visão mais restrita, nos mantém vivos, nos sustenta. Com e tal raciocínio, reescrevo as três normas éticas construídas pelo professor Sirio, acreditando nesses pressupostos como balizadores de nossapráxis político-pedagógica. No entanto, fixá-las como metarregras, que se traduzem, através da lógica linguística, como uma verdade comprovada cientificamente, assusta; não pelo fato de desacreditar da ferramenta linguística, mas por desacreditar em qualquer ciência que postule verdades absolutas.

Ainda assim, é impressionante o modo como a partir de uma lógica tão simples " $\mathrm{Eu}$ faço isto porque isto é condição daquilo", o autor consegue deduzir normas com tamanha abrangência no universo ético, filosófico e social.

Levanta na primeira, a questão fundamental da existência humana, a categoria utópica da liberdade. Nossas decisões devem primar pela busca incessante de uma maior possibilidade de opções e estas se multiplicam no momento em que compartilhamos respostas; e, quando percebemos, estamos caindo na segunda norma, sustentada agora na busca pela construção de uma resposta comum, que atenda aos interesses da comunidade 
na qual se dá nossa práxis social. Já a terceira nos remete para o restante da natureza da qual somos parte, mantendo-a saudável e consequentemente produtiva, garantindo a existência da raça humana. A sociedade que se orienta, assim, pela ética, constitui a ordem socioambiental utópica pós-capitalista (Ecomunitarismo), compreendida como um horizonte sempre mais além para a humanidade, mas que nutre cada ação humana, hoje, de um significado, em última análise, libertário.

\section{A cidade como currículo}

É possível que a categoria mais cara à Pedagogia do Oprimido seja a mais difícil de ser atualizada: a perspectiva revolucionária que deve estar presente em cada ação pedagógica. Quando confrontado com a perspectiva freiriana, em mim, professor, instalase um certo mal-estar, uma vez que não me parece possível encontrar espaço para tais práticas em um ambiente escolar ritualizado pelos ritmos da sociedade pós-industrial, que percebe a criança, o jovem e o adulto sempre como alguém a ser formado ou preparado para a reprodução social, alguém a ser adaptado a um sistema comprovadamente injusto e, por ser assim, torna-se competitivo, violento e bélico.

É na reprodução produtivista que a humanidade deixa de cumprir seu devir emancipatório humanizante e reforça o seu destino presentificado em uma barbárie social.

Tento responder ao mencionado mal-estar com uma prática político-pedagógica que primeiramente deve situar os sujeitos do processo educativo em seu contexto/ ambiência; um estudo da realidade que leva o/a estudante a reconhecer-se no lugar onde vive, reconstruindo laços geográficos, históricos e ambientais trabalhando no sentido de desenvolver o pertencimento a partir da sensibilização. É nessa leitura local nesta observação cotidiana do espaçoque ampliaremos nossas visões de mundo.

Gosto de pensar que, muitas vezes, consigo efetivamente oportunizar um espaço de releitura da realidade. É possível presenciar despertares críticos em processos educativos e, quando isso ocorre, são momentos de rara aprendizagem para nós, professores/as. Então, meu trabalho, minha disciplina, minha rotina universitária parece se estabelecer na busca cuidadosa e atenta de tais momentos.

A surpresa continua sendo nossa melhor ferramenta na construção de um fazer pedagógico que teima andar a contravento; teima dizer não à "neoliberalidade globalitária”, que contamina a alma e tenta arrancar com tecnologia de ponta a humanidade que nunca deixará de residir em nossos corações

Rev. Eletrônica Mestr. Educ. Ambient. Rio Grande. v. 37, n. 3. Seção especial: XI EDEA - Encontro e Diálogos com a Educação Ambiental. p. 365-378. mai./ago. 2020.

E-ISSN 1517-1256 
A necessidade de contextualização, esse pensar acerca do mundo é vital ao processo educativo; a partir do processo de entender/viver o mundo, eu posso agir no sentido de construí-lo e transformá-lo ou, em uma perspectiva mais pobre e funcional da vida, simplesmente posso operar para melhor me adaptar à sociedade.

Logo, o estudo crítico da realidade local e global, partindo da compreensão dos sujeitos e problematizado pelo/a professor/a, é uma primeira e necessária tentativa para afastar nosso mal-estar em relação ao caráter revolucionário da prática educativa.

\section{O processo e algumas descobertas transitórias}

Finalmente podemos perguntar: como a escola organiza e transmite as representações do urbano? Qual o lugar dos lugares de memória nos processos educativos escolares? Se memória se articula comidentidade e projeto é preciso que nos perguntemos: que cidade estamos, ontem e hoje dando a ver/ouvir/sentir/cheirar aos nossos estudantes? (FILHO in BRANDÃO, 2006, p.118)

As estratégias básicas do trabalho são o caminhar, observar e registrar a cidade objetivando sensibilização e pertencimento em um primeiro momento, para logo em seguida ou concomitante, refletir sobre o sociedade e natureza construindo saberes ambientais de forma coletiva na soma das diferentes visões da cidade e diferentes áreas do conhecimento por onde transitamos.

De fato, a cidade tem, como poucas realidades o condão de exigir a mobilização tanto de variadas perspectivas disciplinares, quanto, mais decisivo, é o espaço síntese, por excelência, da vivência social contemporânea em todas as suas virtualidades e desafios. Eleger a cidade debruçar-se sobre ela e buscar compreendê-la, é um imperativo para os que entendem o destino da cidade, em grande medida, o destino do mundo contemporâneo. (BRANDÃO, 2006 p.21).

Sempre quando falo/escrevo, é de algum lugar; sim creio saber também que em mim habitam infinitos lugares e tempos, mas quando caminhamos quero a materialidade e o peso do agora, na tentativa de entender os olhares ocasionais das pessoas que me passam, as cores e formas das fachadas de madeira e de lata, que crescem e se precipitam diante de minha visão e que me servem de cenário da aula, deste ar urbano que respiro. Falo/escrevo de meu porto, meu cais.

São as trilhas urbanas que oferecem à comunidade acadêmica e às comunidades escolares a possibilidade de dimensionar o bairro e seus limites; apresentar a identidade 
geográfica da cidade de Uruguaiana, composta pelo rio Uruguai e seus arroios afluentes; destacar a realidade das comunidades ribeirinhas expostas a biodinâmica do rio e a poluição assustadora de suas margens; resgatar elementos da história arte e arquitetura registrado em museus e fachadas de antigos prédios; entender a importância para a biodiversidade de zonas como a várzea do Cacaréu e suas reduzidas matas ciliares; proporcionar momentos agradáveis de socialização; trabalhar a surpresa como elemento de enriquecimento do fazer pedagógico, aproximando o aprender ao ato de aventura rumo ao desconhecido ou pouco observado; sensibilizar @s caminhantes para as dimensões não humanas da natureza e sua necessária preservação e cuidado; e por fim mas não menos importante, ressaltar a importância do hábito de longas caminhadas como elemento antropológico da cultura corporal de movimento responsável pelo desenvolvimento da inteligência humana, além da já bastante divulgada relação do ato de caminhar com saúde e qualidade de vida.

Manoel de Barros tem uma visão bastante interessante do caminhar e dos andarilhos:

Quero falar primeiro dos andarilhos, do uso que eles fazem da ignorância. Sempre eles sabiam tudo sobre o nada. E ainda multiplicavam por zero-o que lhes dava uma linguagem de chão. Para nunca saber onde chegavam. Eles não afundavam estradas, mas inventavam caminhos. Essa préciência que sempre vi nos andarilhos. Eles me ensinaram a amar a natureza. (2008 p.2)

$\mathrm{O}$ ato de caminhar ainda permite certa apropriação do espaço e imersão em realidades que fazem emergir aprendizagens sensório motoras significativas: "Quanto mais longe caminho, menos distinção faço entre meu corpo, minha mente e o que me rodeia. $\mathrm{O}$ mundo interior e exterior sobrepõem-se. Deixo de ser observador a olhar para a natureza, pois todo o meu corpo está envolvido. (KAGGE, 2018 p.158)

Foram seis trilhas urbanas, assim denominadas por terem seu início e boa parte do percurso na zona urbana da cidade, sendo percorridas por estudantes e professoras de duas escolas públicas (anos finais e ensino médio) e acadêmic@sda turma de CCCG Movimento e Ambiente 20192 dos cursos de Lic. Educação Física e Ciências da Natureza, além das graduações de Enfermagem, Medicina Veterinária e Farmácia.

Exploramos as margens do rio Uruguai e seus arroios afluentes (Salso de Cima, Cacaréu e Salso de Baixo). Como muitas vezes geografia condiciona a história, o mundo físico precede o cultural, descobrimos que os primeiros habitantes da região, o Povo Charrua, montavam seus acampamentos justamente próximos a estes mananciais hídricos, 
antes dos jesuítas e guaranis inventarem a pecuária no RS, mas isto é outra história. Valendo-nos de uma pedagogia das ruas e tendo a cidade como currículo, identificamos através destas expedições com acadêmicos e comunidades escolares ribeirinhas uma possível identidade geográfica para a cidade de Uruguaiana, é composta obviamente pelo Rio Uruguai e seus três arroios desaguantes Salso de Cima, Salso de Baixo e Cacaréu. Os arroios Salso de Cima e Salso de Baixo envolvem quase que completamente a cidade, e o arroio Cacaréu forma uma enorme várzea a quinze minutos do centro de Uruguaiana.

Durante o percurso foram visitados o Museu Raul Pont no centro e o museu do Rio Uruguai no bairro Mascarenhas de Moraes ou popularmente conhecida como Ilha do Marduque, verdadeiras reservas do patrimônio histórico, cultural e artístico do município.Com isto conceitos como várzea, matas ciliares, biodiversidade, povos originários, poluição hídrica, saneamento, educação ambiental, pesca artesanal, mineração, patrimônio cultural, urbanidade, pouco a pouco vão se misturando com saberes da filosofia, arte, biologia, arquitetura...todos cadenciados pelo ritmo do caminhar longas distâncias, fazem nos aproximar de um conceito transdisciplinar ou interdisciplinar caso ainda acreditemos em algum tipo de separação necessária entre as áreas.

Um de nossos primeiros movimentos nas comunidades escolares é a caminhada circundando o bairro pelas suas ruas limítrofes o que torna patente o desconhecimento de estudantes e acadêmicos sobre o lugar onde habitam. Em um dos relatos, um estudante de ensino médio encerra seu texto com a frase centralizada "Eu não conhecia o meu bairro". Sensação que todos, de uma forma ou de outra, acabaram sentindo. A expressão "Eu não sabia que..." aparece em praticamente todos os relatos dos escolares. O que faz com que a escola negligencie tanto os conteúdos locais e os saberes regionais? Suspeito que é por não estarem institucionalizados e ou referenciados pela academia. Aprendemos mais sobre o rio Nilo do que sobre o rio Uruguai. Decoramos a história do Brasil, mas esquecemos a história de Uruguaiana ou do bairro Bela Vista.

Quando é oportunizado aprender com as ruas, com a história em movimento, com a cultura escrita em casas, pessoas, animais e plantas, enfim a céu aberto e em movimento; aprendizagens e conceitos apresentam-se contextualizados e interdisciplinares e já em um primeiro momento instiga professoras e estudantes a refletir sobre seu lugar, entendê-lo e com sorte valorizá-lo. São caminhos para fortalecer o pertencimento tão necessário em comunidades ribeirinhas. Uma das escolas luta contra a falta de alunos; localizada na beira do Rio Uruguai, os moradores preferem escolas centrais no alto da cidade: "Nós queremos subir né professor?"

Rev. Eletrônica Mestr. Educ. Ambient. Rio Grande. v. 37, n. 3. Seção especial: XI EDEA - Encontro e Diálogos com a Educação Ambiental. p. 365-378. mai./ago. 2020. 
Em outra escola ao explorarmos os limites do bairro falei que iríamos encontrar o arroio Salso de Baixo. Um dos professores que nos acompanhava estranhou e até duvidou da existência, já atuava na escola faziam 8 anos e nunca tinha ouvido falar do tal arroio, alguns estudantes mais velhos sabiam da existência, mas foi surpresa para a maioria quando chegamos as margens do calmo arroio, onde se avistam alguns enormes e velhos salsos, árvore comum na região. Um aspecto interessante nestas saídas é a diferença gritante entre os sexos no que se refere ao reconhecimento do bairro e região. Os meninos se encontram muito mais à vontade e conhecedores dos caminhos trilhados.

Em outro relato, agora de uma acadêmica de Enfermagem, podemos perceber a mesma surpresa: "O fato de que, mesmo morando a apenas alguns passos de distância do museu e passar na frente praticamente todos os dias, nunca havia prestado atenção na presença dele, nem manifestado nenhum interesse em conhecê-lo...percebi que de fato, me senti um pouco mais pertencente à rua a qual moro há três anos".

Parece que estes relatos por si só dimensionam o poder pedagógico e rico de significados do ato de caminhar em grupo e suas múltiplas possibilidades de construção de saberes.

Vários registros ressaltam o encontro com um pescador artesanal residente no local ocorrido quando caminhamos até a Foz do Salso de Baixo (A boca do Salso): “Além da beleza natural existente, o humano se introduz a natureza, contemplamos a presença do pescador, um anonimato que em sua fala precisa ser visto e lembrado, argumentos de satisfação e orgulho por fazer parte da natureza, e insatisfação de não ser visto por humanos parecidos com ele, a vida racional e irracional tão próxima e ao mesmo tempo tão distante uma da outra". Todo um projeto de extensão poderia ser originado a partir destes encontros inusitados, destas diferentes realidades que se percebem, universos que se encontram.

Aspecto importante dos registros/relatos que solicitei foi o surgimento de uma linguagem mais metafórica para descrever o sentido/vivido. Uma estudante descreveu o afluente do rio Uruguai como um ramo de uma grande árvore, sintetizando o conceito de rede, bastante caro à EA, houveram registros nas formas de poesia, desenho, fábula, foto, vídeo e ao final do semestre uma mostra ambiental dos trabalhos produzidos.

A produção de dados neste projeto envolvendo ensino/extensão/pesquisa está na sua fase inicial, mas já poderemos apreciar algumas neste XI EDEA elaboradas pelo@s acadêmicos que cursam a CCCG Movimento e Ambiente neste semestre. 


\section{Referências}

BARROS, Manoel. Memórias inventadas: a terceira infância. São Paulo: Editora Planeta, 2008.

BRANDÃO, Carlos Antônio Leite. As cidades da cidade. Belo Horizonte: Editora UFMG, 2006.

FOSTER, John Belamy. A Ecologia de Marx, materialismo e natureza. São Paulo: Civilização Brasileira, 2005.

FREIRE, Paulo. Pedagogia do oprimido. Rio de Janeiro: Paz e Terra, 1987.

MARCUSE, Herbert. A Ideologia da Sociedade Industrial. Rio de Janeiro: Zahar, 1967.

KAGGE, Erling. A arte de caminhar. Um passo de cada vez. Lisboa: Quetzal editores, 2018.

MARX, Karl e ENGELS, Friedrich. A Ideologia Alemã. São Paulo: Martin Claret, 2004.

MARX, Karl. Manuscritos econômico-filosóficos. São Paulo, Boitempo, 2004.

ODUM, Eugene P.; Ecologia. Madri:Interamericana, 1970.

VELASCO, Sirio Lopez. Ética de laliberacion: política sócio-ambientalecomunitarista. Rio Grande: EDGRAF, 2000.

VELASCO, Sirio Lopez. Ética para o século XXI rumo ao ecomunitarismo. São Leopoldo: Gráfica da Unisinos, 2003.

VELASCO, Sirio Lopez. Fundamentos lógico-linguísticos da ética argumentativa. São Leopoldo: Nova Harmonia, 2003.

VELASCO, Sirio Lopez. Introdução à Educação Ambiental Ecomunitarista. Rio Grande: Ed. da FURG, 2008. 